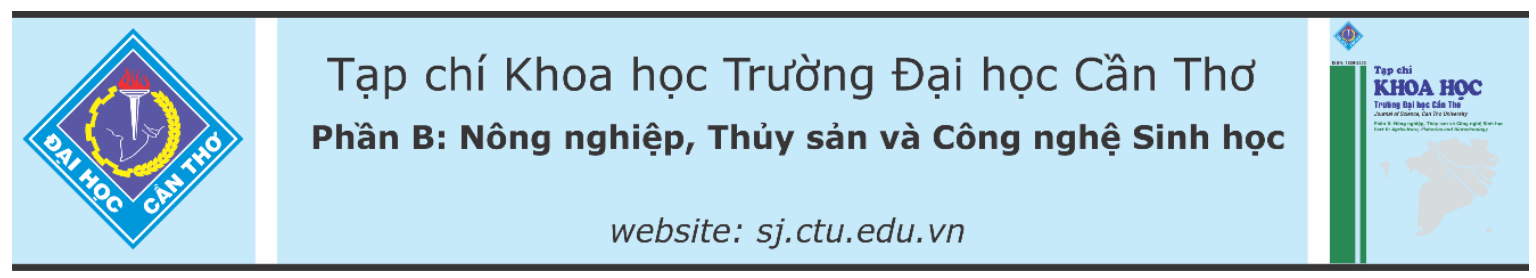

DOI:10.22144/ctu.jvn.2021.017

\title{
ẢNH HƯởNG CỦA DUNG DỊCH DINH DƯỡNG VÀ GIÁ THỂ LÊN SỰ SINH TRƯởNG VÀ PHÁT TRIỂN CỦA CÂY CÚC ĐỒNG TIỀN (Gerbera jamesonii Bolus ex Hooker F.) TRỒNG CHẬU TRONG NHÀ MÀNG SỬ DỤNG HỆ THỐNG TƯớI NHỎ GIỌT
}

\author{
Lê Văn Hòa ${ }^{1 *}$, Lê Bảo Long ${ }^{1}$ và Phạm Thị Xuân Quyên ${ }^{2}$ \\ ${ }^{1}$ Khoa Nông nghiệp, Truờng Đại hoc Cần Tho' \\ ${ }^{2}$ Học viên Cao họ Khoa hoc cây trồng Khóa 22, Khoa Nông nghiệp, Trường Đại học Cần Tho \\ *Người chịu trách nhiệm về bài viết: Lê Văn Hòa (email: lvhoa@ctu.edu.vn)
}

\section{Thông tin chung:}

Ngày nhận bài: $14 / 08 / 2020$

Ngày nhận bài sủa: 01/10/2020

Ngày duyệt đăng: 27/02/2021

\section{Title:}

Effect of nutrient solutions and substrates on growth and development of gerbera (Gerbera jamesonii Bolus ex Hooker F.) cultivating in pot under drip irrigation in the net house

\section{Tù khóa:}

Cúc đồng tiền, dung dịch dinh duõ̃ng, giá thể, nhà màng, trồng chậu, tuới nhỏ giọt

\section{Keywords:}

Drip irrigation, gerbera, net house, nutrient solutions, potting, substrate

\section{ABSTRACT}

The study aimed to evaluate the suitable kind of nutrient solutions and substrates for cultivating commercial gerbera in pot under drip irrigation in the net house. The experiment was laid out in Complete Randomised Design (CRD), two factors including three nutrient solutions (Hoagland, Çolakoğlu-2 and Johnson; tap water) (factor A) and three substrates (coconut fiber dust, ripping straw, coconut fiber dust + ripping straw (1:1) (factor B). The experiment was included 12 treatments with five replications, five plants (pots) for each replication. The results showed that, potting gerbera applied a drip irrigation system using Johnson solution showed maximum plant height, number of roots, flower stalk length, flower diameter and longest flowering duration (12.9 days). Potting gerbera cultivating on ripping straw or coconut fiber dust + ripping straw (1:1) substrates used a drip irrigation system showed maximum plant height, number of leaves per plant, number of roots, number of flowers/plant, flower stalk length and flower diameter.

\section{TÓM TẮT}

Nghiên cưu này nhằm xác định loại dung dịch dinh duõ̃ng và giá thể thích hợp cho hệ thống tuoới nhỏ giọt cây cúc đồng tiền trồng chậu trong nhà màng. Thi nghiệm được bố tri theo thể thức hoàn toàn ngẫu nhiên, 2 nhân tố gồm 3 loại dung dịch dinh duõng (Hoagland, Çolakoğlu-2 và Johnson; đối chứng là nuoớc máy) (nhân tố A) và 3 loại giá thể (mụn xơ dìa, phân rơm, mụn xo dùa + phân rơm tỉ lẹ 1:1) (nhân tố B). Thí nghiệm gồm có 12 nghiệm thức, mối nghiệm thức có 5 lần lạ̣p lại, mối lần lạ̣p lại 5 cây (chạu). Kết quả thí nghiệm cho thấy, cây cúc đồng tiền trồng chậu trong nhà màng tuoói nhỏ giọt với dung dịch dinh duõng Johnson giúp gia tăng chiều cao cây, số rễ, chiều dài phát hoa, đường kính hoa và kéo dài độ bền hoa nở (12,9 ngày). Giá thể phân rơm hoạc mụn xơ dùa + phân rơm (tỉ lệ 1:1) có sư dụng hệ thống tuoói nhỏ giọt giúp gia tăng chiều cao cây, số lá, số rễ, tổng số hoa/cây, chiều dài phát hoa và đường kính hoa. 


\section{GIỚI THIỆU}

Cúc đồng tiền là một loài hoa đa dạng màu sắc: đỏ, cam, vàng, trắng, tím,... ưu điểm hoa cúc đồng tiền khi nở có độ bền lâu, ra hoa quanh năm nên thích hợp làm hoa trang trí và hoa cắt cành. Ngày nay, nhiều loại hoa và kiểng lá đã được trồng thủy canh để đáp ứng nhu cầu giải trí, kinh doanh, sản xuất quy mô công nghiệp. Bên cạnh đó, kỹ thuật canh tác thủy canh đã được sử dụng trong nhiều năm nay ở các nước Địa Trung Hải và châu Âu (Maloupa et al., 1992; Brun et al., 2001). Hệ thống tưới nhỏ giọt kết hợp với cung cấp dinh dưỡng theo nhu cầu của cây trồng ngày càng được ứng dụng rộng rãi trên thế giới vì tiết kiệm nước và dinh dưỡng. Dinh dưỡng có vai trò quan trọng cho sự tăng trưởng và gia tăng năng suất cây trồng. Tùy từng loại giống cây trồng mà có nhu cầu dinh dưỡng khác nhau, vì thế khi cung cấp dinh dưỡng cho cây trồng không phù hợp có thể dẫn đến một số rối loạn sinh lý có thể xảy ra (Resh, 1991). Một công thức dinh dưỡng tối ưu phụ thuộc vào loài thực vật và giống cây trồng, giai đoạn sinh trưởng của cây, điều kiện thời tiết như nhiệt độ, cường độ ánh sáng, giờ nắng. Tuy nhiên, chưa có nhiều nghiên cứu tại Việt Nam được công bố về công thức dung dịch dinh dưỡng cho từng loài cây trồng, đặc biệt là trên cây cúc đồng tiền, trồng trong nhà màng sử dụng hệ thống tưới nhỏ giọt. Chính vì vậy, nghiên cứu này được thực hiện nhằm xác định loại dung dịch dinh dưỡng và giá thể thích hợp cho sản xuất hoa chậu cúc đồng tiền áp dụng hệ thống tưới nhỏ giọt trong nhà màng.

\section{PHƯƠNG PHÁP NGHIÊN CÚU}

\subsection{Vật liệu và phương pháp nghiên cứu}

Thí nghiệm được thực hiện tại nhà màng Trại Tân Khánh Đông - Trung tâm Úng dụng Nông nghiệp Công nghệ cao Đồng Tháp từ tháng 08/2016 đến tháng 05/2017 (nhà màng có quạt lưu thông không khí, nhiệt độ trong thời gian thí nghiệm dao động $27-42,7^{\circ} \mathrm{C}$ và ẩm độ từ $21-90 \%$ ).

Đối tượng thí nghiệm: giống cúc đồng tiền màu cam viền vàng (Gerbera jamesonii) cấy mô đã được thuần dưỡng (ra ngôi, 03 tháng tuổi) có chiều cao 10 $-15 \mathrm{~cm}, 5-7$ lá thật (Hình 1B). Giá thể gồm mụn xơ dừa, phân rơm.

Hóa chất: các loại hóa chất đa vi lượng dùng để pha môi trường dung dịch dinh dưỡng Hoagland (Epstein, 1972), Çolakoğlu-2 (Kılınç, 2005), Johnson (Bảng 1). Hóa chất tinh khiết xuất xứ từ Trung Quốc gồm: $\mathrm{KNO}_{3}, \mathrm{NH}_{4} \mathrm{NO}_{3}, \mathrm{KH}_{2} \mathrm{PO}_{4}$, $\mathrm{NH}_{4} \mathrm{H}_{2} \mathrm{PO}_{4}, \mathrm{Ca}\left(\mathrm{NO}_{3}\right)_{2}, \mathrm{MgSO}_{4}, \mathrm{H}_{3} \mathrm{BO}_{3}, \mathrm{MnSO}_{4}$, $\mathrm{ZnSO}_{4} .7 \mathrm{H}_{2} \mathrm{O}, \mathrm{CuSO}_{4}, \mathrm{Na}_{2} \mathrm{MoO}_{4} .2 \mathrm{H}_{2} \mathrm{O}, \mathrm{KCl}, \mathrm{MnCl}_{2}$, $\mathrm{CuCl}_{2}, \mathrm{NaEDTA}_{2} \mathrm{FeSO}_{4} .7 \mathrm{H}_{2} \mathrm{O} \ldots$

Bảng 1. Thành phần khoáng (ppm) của môi trường dung dịch dinh dưỡng Hoagland (Epstein, 1972), Çolakoğlu-2 (Kılınç, 2005), Johnson (Johnson, 1980)

\begin{tabular}{lrrrrrrrrrrrr}
\hline Môi trường & \multicolumn{10}{c}{ Thành phần dinh dưỡng khoáng (ppm) } \\
\cline { 2 - 13 } dinh dưỡng & $\mathbf{N}$ & $\mathbf{P}$ & $\mathbf{K}$ & $\mathbf{C a}$ & $\mathbf{M g}$ & $\mathbf{S}$ & $\mathbf{F e}$ & $\mathbf{B}$ & $\mathbf{M n}$ & $\mathbf{Z n}$ & $\mathbf{C u}$ & Mo \\
\hline Hoagland & 224 & 62 & 235 & 160 & 24 & 32 & 3,0 & 0,27 & 0,11 & 0,13 & 0,03 & 0,05 \\
Çolakoğlu-2 & 150 & 31 & 234 & 100 & 30 & 15 & 8 & 1,5 & 5 & 3 & 2 & 0,2 \\
Johnson & 105 & 33 & 138 & 85 & 25 & 33 & 2,3 & 0,23 & 0,26 & 0,024 & 0,01 & 0,007 \\
\hline
\end{tabular}
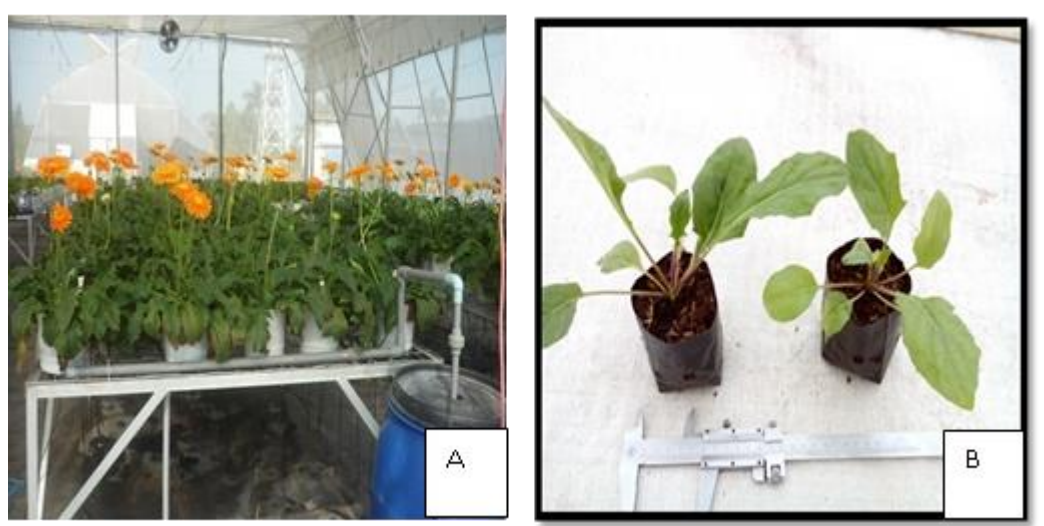

Hình 1. Nhà màng có quạt lưu thông không khí $(\mathrm{A})$ và cây con cấy mô hoa cúc đồng tiền $(\mathrm{B})$

Mụn xơ dừa được ngâm với dung dịch nước vôi $5 \%$ trong thời gian 15 ngày, sau đó ngâm xả vôi 03-
04 lần bằng nước, đem phơi ráo rồi mới cho vào chậu nhựa trắng tròn $(18 \times 18 \times 15 \mathrm{~cm})$. Các giá thể 
đều được trộn và ủ với Tricoderma trước khi cho vào chậu, trồng 01 cây/chậu. Cây ổn định sau 2 tuần, tiến hành bố trí thí nghiệm.

Các loại dinh dưỡng được pha với nước máy ( $\mathrm{pH}$ $7,0 \pm 0,5)$, sau khi pha dung dịch dinh dưỡng điều chỉnh $\mathrm{pH}$ ở giá trị 6,5. Hệ thống tưới nhỏ giọt bù áp lưu lượng tối đa mỗi đầu $5 \mathrm{ml} /$ phút. Cài đặt hẹn giờ, chia đều lượng nước tưới trong thời gian từ 8 giò̀ sáng đến 4 giờ chiều, đặt điểm tưới nhiều lần/ngày. Trong quá trình thí nghiệm, phòng trị sâu bệnh định kỳ 10 ngày/lần.

\subsection{Phương pháp đánh giá chỉ tiêu}

Ghi nhận các chỉ tiêu: $\mathrm{pH}, \mathrm{EC}(\mathrm{mS} / \mathrm{cm})$ của dung dịch dinh dưỡng; nhiệt độ, ẩm độ, $\mathrm{EC}$ của giá thể sau khi tưới ( $\mathrm{EC}$ đo bằng bút đo $\mathrm{EC}$ hiệu Hanna HI98331). Nhiệt độ và ẩm độ không khí, ánh sáng trong nhà màng đo lúc 8,12 và 17 giờ. Đo lần đầu ngay khi trồng, các lần kế tiếp cách nhau 10 ngày.

Theo dõi các chỉ tiêu sinh trưởng và phát triển của cây ghi nhận tại thời điểm 140 ngày sau khi trồng (ngày $\mathrm{SKT}$ ), 5 cây/nghiệm thức và tính trung bình: chiều cao cây ( $\mathrm{cm}$, đo từ mặt giá thể đến đỉnh lá dài nhất), số lá/cây (đếm tổng số lá trên cây), số rễ/cây (đếm tất cả các rễ).

Các chỉ tiêu năng suất và chất lượng hoa: tổng số hoa/cây (đếm tất cả các hoa nở trên cây), chiều dài phát hoa $(\mathrm{cm}$, đo từ mặt giá thể đến cồ hoa), đường kính hoa $(\mathrm{cm}$, đo khi hoa nở đạt kích thước tối đa), đường kính phát hoa $(\mathrm{cm}$, lấy trung bình ở tại trung điểm, gốc phát hoa và cổ hoa), độ bền hoa (tính từ ngày hoa nở đạt kích thước tối đa đến khi cánh hoa bị héo). Đo ở hoa nở đầu tiên trên chậu, mỗi lặp lại theo dõi 1 hoa.

\subsection{Xử lý số liệu}

Xử lý số liệu bằng chương trình SPSS 21.0, phân tích phương sai, so sánh các giá trị trung bình bằng phép thử DUNCAN ở mức ý nghĩa 5\% hoặc $1 \%$.

\section{KẾT QUẢ VÀ THẢO LUẬN}

\subsection{Ghi nhận tổng quát}

Kết quả ghi nhận giá trị EC của dung dịch Hoagland, Çolakoğlu-2, Jonhson và nước (đối chứng) được ghi nhận lần lượt là 2,$15 ; 1,92 ; 1,32$ và $0,13(\mathrm{mS} / \mathrm{cm})$. Trong thành phần nước máy vẫn có khoáng chất nhưng thấp, dinh dưỡng Hoagland có giá trị $\mathrm{EC}$ cao nhất. Giá trị $\mathrm{pH}$ của các dung dịch dinh dưỡng dao động 6,3-6,5. Theo Ludwing et al. (2010), pH giá thể nhỏ hơn 5 và cao hơn 7 thì không thích hợp cho sự phát triển của cây cúc đồng tiền. $\mathrm{EC}$ của giá thể được ghi nhận cho thấy, mụn xơ dừa có giá trị EC thấp $(0,57-0,88 \mathrm{mS} / \mathrm{cm})$, phân rơm (0,63-1,23 mS/cm), mụn xơ dừa + phân rơm $(0,66$ $1,22 \mathrm{mS} / \mathrm{cm})$. Theo Nguyễn Bảo Toàn (2010), EC lý tưởng cho thủy canh là $1,5-2,5 \mathrm{dS} / \mathrm{m}$, trong điều kiện nhà lưới, nhà kính chỉ số $\mathrm{EC}$ thích hợp là $0,8-5,0$ $\mathrm{dS} / \mathrm{m}$. Tuy nhiên, chỉ số $\mathrm{EC}$ còn phụ thuộc vào từng loại cây trồng, cây đỗ quyên EC thích hợp là $0,8-1,2$ $\mathrm{dS} / \mathrm{m}$, nhưng đối với African violet và cây hoa đồng tiền chỉ số EC thích hợp từ 1,2 -1,5 dS/m (Kessler, 1999; Adam, 2002). EC thấp thường sẽ thuận lợi cho sự phát triển của thực vật, giúp cây hấp thu khoáng chất nhanh hơn hấp thu nước và ngược lại. Trong giai đoạn cây tăng trưởng mạnh sẽ hấp thu nhiều dinh dưỡng làm cho $\mathrm{EC}$ giảm nhanh, do đó cần cung cấp lượng dinh dưỡng để cây tăng trưởng. Tuy nhiên, khi EC tăng quá cao sẽ hạn chế sự hấp thu dinh dưỡng của cây trồng (Gislerød et al., 2005).

Giá trị $\mathrm{pH}$ của giá thể mụn xơ dừa $(5,7-5,8)$, phân rơm $(6,6-6,8)$ và mụn xơ dừa + phân rơm $(6,5-6,8)$. Theo Taiz and Zeiger (1998), $\mathrm{pH}$ của giá thể nằm trong khoảng acid nhẹ 5,5-6,5 thích hợp cho nhiều loại cây, cây trồng dễ dàng hút dinh dưỡng.

Điều kiện ngoại cảnh tại Trại Tân Khánh Đông, thành phố Sa Đéc, Đồng Tháp cho thấy, thời điểm 12 giờ nhiệt độ lên cao nhất trung bình $39^{\circ} \mathrm{C}$, ẩm độ thấp $34,1 \%$ và cường độ ánh sáng trong nhà màng trung bình đạt 15.377 lux (Bảng 2).

Bảng 2. Biến động nhiệt độ, ẩm độ không khí, cường độ ánh sáng trong ngày trong nhà màng trồng cúc đồng tiền tại Trại Tân Khánh Đông, thành phố Sa Đéc, Đồng Tháp

\begin{tabular}{crrr}
\hline Thời gian (giờ) & Nhiệt độ $\left({ }^{\circ} \mathbf{C}\right)$ & Ầm độ (\%) & Cường độ ánh sáng (lu \\
\hline 08 & 29,4 & 81,6 & 731 \\
12 & 39,0 & 34,1 & 15.387 \\
17 & 28,3 & 48,3 & 598 \\
\hline
\end{tabular}

Theo Thiên Kim (2009), nhiệt độ là một trong những yếu tố quan trọng quyết định sự sinh trưởng, phát triển của cây, đa số các giống hoa đồng tiền ưa khí hậu mát mẻ, nhiệt độ thích hợp từ $18-25^{\circ} \mathrm{C}$. Bên cạnh đó, có một số giống thích hợp với nhiệt độ cao từ $30-34^{\circ} \mathrm{C}$. Hoa đồng tiền chịu được dưới ánh sáng toàn phần nhưng cây phát triển mạnh khi che sáng 30-50\%. Trồng trong điều kiện ánh sáng thích hợp cây sinh trưởng mạnh, cho nhiều hoa, màu sắc đẹp và độ bền hoa cao (Kessler, 1999). 
3.2. Ảnh hưởng của dung dịch dinh dưỡng và giá thể lên sự sinh trưởng và phát triển của cây cúc đồng tiền sử dụng cho hệ thống tưới nhỏ giọt

\subsubsection{Anh huơơng đến chiều cao cây}

Bảng 3 cho thấy chiều cao cây cúc đồng tiền cao nhất ở nghiệm thức dung dịch Johnson khác biệt có ý nghĩa thống kê ở mức $1 \%$ so với các nghiệm thức còn lại. Giá thể phân rơm và mụn xơ dừa + phân rơm có chiều cao cây cúc đồng tiền khác biệt không có ý nghĩa qua phân tích thống kê và cao hơn so với chiều cao cây cúc đồng tiền trồng trên giá thể mụn xơ dừa. Có sự tương tác giữa dung dịch dinh dưỡng và giá thể trồng, trồng cây cúc đồng tiền trên giá thể phân rơm kết hợp hệ thống tưới nhỏ giọt với dung dịch dinh dưỡng Çolakoğlu-2 có chiều cao cây cao hơn các nghiệm thức còn lại, ngoại trừ nghiệm thức trồng trên giá thể mụn xơ dừa kết hợp với dung dịch dinh dưỡng Hoagland. Theo Steiner (1961), thành phần dinh dưỡng khác nhau có tác động đến giá thể trồng lên chiều cao cây. Nồng độ ion tổng của một dung dịch dinh dưỡng quyết định sự tăng trưởng, phát triển và năng suất cây trồng. Kết quả cho thấy, cây cúc đồng tiền trồng trên các giá thể chỉ tưới nước thì cây vẫn sống, do giá thể và trong nước vẫn có các khoáng chất cung cấp tối thiểu cho cây trồng, mặc dù cây còi cọc hơn so với cây cung cấp dinh dưỡng.

Bảng 3. Ảnh hưởng của dung dịch dinh dưỡng và giá thể đến sự sinh trưởng của cây cúc đồng tiền giai đoạn 140 ngày sau khi trồng

\begin{tabular}{|c|c|c|c|c|}
\hline \multirow[b]{2}{*}{ Dinh dưỡng (A) } & \multirow{2}{*}{ Giá thể (B) } & \multicolumn{3}{|c|}{ Các chỉ tiêu sinh trưởng } \\
\hline & & Chiều cao cây $(\mathrm{cm})$ & Số lá & Số rễ̂ \\
\hline \multirow{3}{*}{ Nước } & Mụn xơ dừa & $28,5 \mathrm{f}$ & $20,8 \mathrm{~g}$ & $13,5 \mathrm{e}$ \\
\hline & Phân rơm & $36,1 \mathrm{c}$ & $35,8 \mathrm{f}$ & $46,3 \mathrm{~d}$ \\
\hline & Mụn xơ dừa + phân rơm & $35,4 \mathrm{~cd}$ & 43,3 a & $51,2 \mathrm{~d}$ \\
\hline \multirow{3}{*}{ Hoagland } & Mụn xơ dừa & $40,0 \mathrm{ab}$ & $37,1 \mathrm{e}$ & $\overline{63,0 \mathrm{c}}$ \\
\hline & Phân rơm & 34,0 de & $37,6 \mathrm{e}$ & $84,0 \mathrm{~b}$ \\
\hline & Mụn xơ dừa + phân rơm & $39,3 \mathrm{~b}$ & $39,0 \mathrm{~cd}$ & $111,9 \mathrm{a}$ \\
\hline \multirow{3}{*}{ Çolakoğlu-2 } & Mụn xơ dừa & $36,2 \mathrm{c}$ & $39,6 \mathrm{c}$ & $63,5 \mathrm{c}$ \\
\hline & Phân rơm & $41,3 \mathrm{a}$ & $42,4 \mathrm{ab}$ & $85,6 \mathrm{~b}$ \\
\hline & Mụn xơ dừa + phân rơm & $33,5 \mathrm{e}$ & $35,7 \mathrm{f}$ & $111,6 \mathrm{a}$ \\
\hline \multirow{3}{*}{ Johnson } & Mụn xơ dừa & $39,5 \mathrm{~b}$ & $38,1 \mathrm{dc}$ & $65,0 \mathrm{c}$ \\
\hline & Phân rơm & $36,9 \mathrm{c}$ & $41,6 \mathrm{~b}$ & $87,1 \mathrm{~b}$ \\
\hline & Mụn xơ dừa + phân rơm & $39,3 \mathrm{~b}$ & $38,1 \mathrm{de}$ & $111,5 \mathrm{a}$ \\
\hline \multicolumn{5}{|l|}{ Dinh dưỡng $(\mathrm{A})$} \\
\hline \multicolumn{2}{|l|}{ Nước } & $32,0 \mathrm{~d}$ & $31,4 \mathrm{~d}$ & $37,0 \mathrm{~b}$ \\
\hline \multicolumn{2}{|l|}{ Hoagland } & $38,3 \mathrm{~b}$ & $37,6 \mathrm{c}$ & $86,3 \mathrm{a}$ \\
\hline \multicolumn{2}{|l|}{ Çolakoğlu } & $36,2 \mathrm{c}$ & $41,5 \mathrm{a}$ & $87,0 \mathrm{a}$ \\
\hline \multicolumn{2}{|l|}{$\frac{\text { Johnson }}{\text { Giá thể (B) }}$} & $40,2 \mathrm{a}$ & $39,2 \mathrm{~b}$ & $89,0 \mathrm{a}$ \\
\hline \multicolumn{5}{|l|}{ Giá thể (B) } \\
\hline \multicolumn{2}{|l|}{ Mụn xơ dừa } & $35,0 \mathrm{~b}$ & $34,2 \mathrm{c}$ & $51,3 \mathrm{c}$ \\
\hline \multicolumn{2}{|l|}{ Phân rơm } & $37,7 \mathrm{a}$ & 39,7 a & $75,7 \mathrm{~b}$ \\
\hline \multicolumn{2}{|c|}{ Mụn xơ dừa + phân rơm } & $37,3 \mathrm{a}$ & $38,4 \mathrm{~b}$ & $97,5 \mathrm{a}$ \\
\hline \multicolumn{2}{|l|}{$\mathrm{F}(\mathrm{A})$} & ** & $* *$ & ** \\
\hline \multicolumn{2}{|l|}{$\mathrm{F}(\mathrm{B})$} & ** & $* *$ & * \\
\hline \multicolumn{2}{|l|}{$\mathrm{F}(\mathrm{AxB})$} & ** & $* *$ & * \\
\hline \multicolumn{2}{|l|}{$\mathrm{CV}(\%)$} & 3,4 & 2,5 & 5,3 \\
\hline
\end{tabular}

Ghi chú: Nhũng số có chũ theo sau giống nhau trong cùng một cột thì khác biệt không ý nghĩa thống kê qua phép thử Duncan; ** khác biệt có ý nghĩa thống kê ở múc $1 \%$

\subsubsection{Anh hương đến số lá}

Số lá cây cúc đồng tiền chịu tác động bởi loại giá thể trồng và dinh dưỡng cung cấp cho cây. Tại thời điểm 140 ngày SKT, dung dịch dinh dưỡng Çolakoğlu-2, giá thể phân rơm có số lá trên cây nhiều nhất. Giá thể mụn xơ dừa + phân rơm kết hợp hệ thống tưới nhỏ giọt với nước có số lá trên cây nhiều nhưng khác biệt không có ý nghĩa thống kê so với số lá trên cây ở nghiệm thức giá thể phân rơm kết hợp với dung dịch dinh dưỡng Çolakoğlu. Theo Edwards and Bell (1989), trong rơm rạ chứa khoảng $0,6 \% \mathrm{~N}, 0,1 \% \mathrm{P}, 0,1 \% \mathrm{~S}, 1,5 \% \mathrm{~K}, 5 \% \mathrm{Si}$ và $40 \% \mathrm{C}$. Trong giai đoạn sinh trưởng của cây, quá trình phân hủy rơm rạ vẫ் tiếp tục diễn ra và tăng hàm lượng các chất đạm, lân, kali và một số chất vi lượng và hữu cơ cung cấp cho cây. Giá thể mụn dừa cho số lá trung bình thấp là do tính chất của mụn dừa có tỉ lệ $\mathrm{C} / \mathrm{N}$ cao (tỉ lệ $\mathrm{C} / \mathrm{N}$ khoảng $80 / 1$ ) thành phần hữu cơ 
thấp dẫn đến giảm lượng dinh dưỡng hữu dụng quan trọng đối với sinh trưởng của cây trồng (Şirin, 2011).

\subsubsection{Anh hương đến số rễ}

Kết quả khảo sát trình bày ở Bảng 3 cho thấy cây cúc đồng tiền được tưới nhỏ giọt với dung dịch dinh dưỡng Johnson, Çolakoğlu-2 và Hoagland có số rễ không khác biệt nhau qua phân tích thống kê (89; $87 ; 86,3$ rễ) nhưng số rễ nhiều hơn so với đối chứng (nước, 37 rễ). Giá thể mụn xơ dừa + phân rơm có số rễ đạt nhiều nhất so với giá thể mụn xơ dừa và giá thể phân rơm. Trồng cúc đồng tiền trên giá thể mụn xơ dừa + phân rơm kết hợp tưới nhỏ giọt với dung dịch dinh dưỡng Hoagland, Çolakoğlu-2 và Johnson đều cho số rễ nhiều so với chỉ cung cấp dinh dưỡng với nước. Theo kết quả nghiên cứu của Thái Hoàng Phúc (2011), giá thể xơ dừa + tro trấu + cát + phân hữu cơ vi sinh + đất phối trộn theo tỷ lệ 4:4:2:1:11 thích hợp cho cây cúc đồng tiền cấy mô trong giai đoạn thuần dưỡng, cây tăng trưởng nhanh, số rễ nhiều và tỷ lệ sống cao.

\section{3. Ảnh hưởng của dung dịch dinh dưỡng và} giá thể lên năng suất và chất lượng của cây cúc đồng tiền sử dụng cho hệ thống tưới nhỏ giọt

Bảng 4 cho thấy các chỉ tiêu về năng suất và chất lượng của hoa cúc đồng tiền thay đổi theo loại dinh dưỡng và giá thể trồng khi áp dụng hệ thống tưới nhỏ giọt, khác biệt có ý nghĩa thống kê. Khảo sát tại thời điểm 140 ngày SKT, tổng số hoa trên cây đạt nhiều nhất ở môi trường dung dịch dinh dưỡng Hoagland và Çolakoğlu-2 (7,8-7,9 hoa/cây), tưới nhỏ giọt cho cây cúc đồng tiền với nước (đối chứng) cây vẫn cho ra hoa nhưng tổng số hoa trên cây ít nhất (4,8 hoa/cây). Giá thể phân rơm cho tổng số hoa trên cây đạt nhiều nhất $(7,4$ hoa/cây). Tổng số hoa/cây thể hiện nhiều nhất khi có sự kết hợp giữa giá thể mụn xơ dừa và dung dịch dinh dưỡng Johnson, Çolakoğlu-2. Tuy nhiên, đối với dung dịch dinh dưỡng nước (đối chứng) trồng trên giá thể mụn xơ dừa có số hoa/cây ít nhất, nhưng khi trồng trền giá thể mụn xơ dừa + phân rơm với tỉ lệ $1: 1$ thể hiện số hoa/cây đạt nhiều.

Bảng 4. Ảnh hưởng của dung dịch dinh dưỡng và giá thể đến năng suất và chất lượng của hoa cúc đồng tiền giai đoạn 140 ngày sau khi trồng

\begin{tabular}{|c|c|c|c|c|c|c|}
\hline \multirow[b]{2}{*}{$\begin{array}{l}\text { Dinh dưỡng } \\
\text { (A) }\end{array}$} & \multirow[b]{2}{*}{$\begin{array}{l}\text { Giá thể } \\
\text { (B) }\end{array}$} & \multicolumn{5}{|c|}{ Các chỉ tiêu năng suất và chất lượng } \\
\hline & & $\begin{array}{l}\text { Tổng số } \\
\text { hoa/cây }\end{array}$ & $\begin{array}{r}\text { Chiều dài phát } \\
\text { hoa (cm) }\end{array}$ & $\begin{array}{r}\text { Đường kính } \\
\text { hoa }(\mathbf{c m}) \\
\end{array}$ & $\begin{array}{r}\text { Đưò̀ng kính } \\
\text { phát hoa }(\mathrm{cm})\end{array}$ & $\begin{array}{r}\text { Độ bền } \\
\text { hoa (ngày) } \\
\end{array}$ \\
\hline \multirow{3}{*}{ Nước } & Mụn xơ dừa & $0,63 \mathrm{i}$ & $19,4 \mathrm{e}$ & $3,2 \mathrm{~g}$ & $0,26 \mathrm{e}$ & 10,5 \\
\hline & Phân rơm & $7,1 \mathrm{de}$ & $34,3 \mathrm{c}$ & $11,1 \mathrm{bc}$ & $0,44 \mathrm{c}$ & 12,8 \\
\hline & Mụn xơ dừa + phân rơm & $7,9 \mathrm{abc}$ & $34,3 \mathrm{c}$ & $11,3 \mathrm{bc}$ & $0,46 \mathrm{bc}$ & 12,7 \\
\hline \multirow{3}{*}{ Hoagland } & Mụn xơ dừa & $6,5 \mathrm{f}$ & $41,3 \mathrm{ab}$ & $12,6 \mathrm{a}$ & $0,62 \mathrm{a}$ & 13,4 \\
\hline & Phân rơm & $7,1 \mathrm{de}$ & $31,4 \mathrm{~d}$ & $8,7 \mathrm{e}$ & $0,30 \mathrm{~d}$ & 11,2 \\
\hline & Mụn xơ dừa + phân rơm & $7,8 \mathrm{~cd}$ & $40,6 \mathrm{ab}$ & $11,8 \mathrm{ab}$ & $0,48 \mathrm{~b}$ & 12,3 \\
\hline \multirow{3}{*}{ Çolakoğlu-2 } & Mụn xơ dừa & $8,3 \mathrm{abc}$ & $38,4 \mathrm{~b}$ & $11,7 \mathrm{ab}$ & $0,43 \mathrm{c}$ & 12,5 \\
\hline & Phân rơm & $6,6 \mathrm{ef}$ & $39,4 \mathrm{~b}$ & $10,7 \mathrm{~cd}$ & $0,45 \mathrm{bc}$ & 12,1 \\
\hline & Mụn xơ dừa + phân rơm & $4,9 \mathrm{~h}$ & $32,3 \mathrm{~cd}$ & $9,8 \mathrm{~d}$ & $0,23 \mathrm{e}$ & 11,1 \\
\hline \multirow{3}{*}{ Johnson } & Mụn xơ dừa & $8,4 \mathrm{ab}$ & $41,3 \mathrm{ab}$ & $10,7 \mathrm{~cd}$ & $0,48 \mathrm{~b}$ & 12,8 \\
\hline & Phân rơm & $7,6 \mathrm{~cd}$ & $38,2 \mathrm{~b}$ & $11,8 \mathrm{ab}$ & $0,45 \mathrm{bc}$ & 12,4 \\
\hline & Mụn xơ dừa + phân rơm & $5,7 \mathrm{~g}$ & $43,0 \mathrm{a}$ & $12,4 \mathrm{a}$ & $0,48 \mathrm{~b}$ & 13,4 \\
\hline \multicolumn{7}{|c|}{ Dinh dưỡng (A) } \\
\hline \multicolumn{2}{|l|}{ Nước } & $4,8 \mathrm{c}$ & $28,3 \mathrm{e}$ & $7,5 \mathrm{c}$ & $0,27 \mathrm{c}$ & $\overline{11,0 \mathrm{~b}}$ \\
\hline \multicolumn{2}{|l|}{ Hoagland } & $7,8 \mathrm{a}$ & $38,7 \mathrm{~b}$ & $11,2 \mathrm{~b}$ & $0,47 \mathrm{~b}$ & $12,6 \mathrm{a}$ \\
\hline \multicolumn{2}{|l|}{ Çolakoğlu } & $7,9 \mathrm{a}$ & $38,3 \mathrm{~b}$ & $11,6 \mathrm{ab}$ & $0,45 \mathrm{~b}$ & $12,5 \mathrm{a}$ \\
\hline \multicolumn{2}{|l|}{ Johnson } & $6,3 \mathrm{~b}$ & $41,2 \mathrm{a}$ & $11,9 \mathrm{a}$ & $0,52 \mathrm{a}$ & $12,9 \mathrm{a}$ \\
\hline \multicolumn{7}{|l|}{ Giá thể (B) } \\
\hline \multicolumn{2}{|l|}{ Mụn xơ dừa } & $6,1 \mathrm{c}$ & $34,0 \mathrm{~b}$ & $9,9 \mathrm{~b}$ & $0,45 \mathrm{a}$ & $\overline{12,4}$ \\
\hline \multicolumn{2}{|l|}{ Phân rơm } & $7,4 \mathrm{a}$ & $37,4 \mathrm{a}$ & $10,7 \mathrm{a}$ & $0,42 \mathrm{~b}$ & 12,0 \\
\hline \multicolumn{2}{|c|}{ Mụn xơ dừa + phân rơm } & $6,7 \mathrm{~b}$ & $38,7 \mathrm{a}$ & $11,2 \mathrm{a}$ & $0,42 \mathrm{~b}$ & 12,4 \\
\hline \multicolumn{2}{|l|}{$\mathrm{F}(\mathrm{A})$} & $* *$ & $* *$ & $* *$ & $* *$ & $* *$ \\
\hline \multicolumn{2}{|l|}{ F (B) } & $* *$ & $* *$ & $* *$ & $* *$ & ns \\
\hline \multicolumn{2}{|l|}{$F(A x B)$} & $* *$ & $* *$ & $* *$ & $* *$ & ns \\
\hline \multicolumn{2}{|l|}{$\mathrm{CV}(\%)$} & 5,4 & 5,9 & 7,0 & 23,5 & 7,0 \\
\hline
\end{tabular}

Ghi chú: Nhũng số có chũ theo sau giống nhau trong cùng một cột thì khác biệt không ý nghĩa thống kê qua phép thử Duncan; ** khác biệt có ý nghĩa thổng kê ở múc 1\%; ns: không khác biệt. 
Bảng 4 cho thấy dung dịch dinh dưỡng và giá thể khác nhau đều cải thiện các chỉ tiêu năng suất và chất lượng hoa cúc đồng tiền tại thời điểm 140 ngày SKT. Trong đó, dung dịch dinh dưỡng Johnson giúp gia tăng chiều dài phát hoa, đường kính hoa và đường kính phát hoa. Cả ba loại dung dịch Hoagland, Çolakoğlu-2 và Johnson đều kéo dài thời gian hoa nở, độ bền của hoa cúc đồng tiền (12,5-12,9 ngày) khác biệt có ý nghĩa qua phân tích thống kê so với dung dịch tưới nhỏ giọt đối chứng (nước). Giá thể phân rơm và mụn xơ dừa + phân rơm với tỉ lệ 1:1 giúp gia tăng chiều dài phát hoa và đường kính hoa. Giá thể mụn xơ dừa giúp gia tăng đường kính phát hoa, khác biệt qua phân tích thống kê ở mức ý nghĩa $1 \%$ so với hai giá thể phân rơm và mụn xơ dừa + phân rơm. Tuy nhiên, giá thể chưa thể hiện sự khác biệt về độ bền của hoa cúc đồng tiền tại thời điểm 140 ngày SKT.

Theo Savvas and Gizas (2002), để gia tăng sản lượng và chất lượng hoa ngoài giá trị $\mathrm{EC}$ và $\mathrm{pH}$ của giá thể trồng thì cân bằng N-P-K, Ca-K, N-K, K-Mg và cân bằng các nguyên tố đa và vi lượng trong dung dịch dinh dưỡng cũng đã tác động đến sự sinh trưởng và phát triển hoa.

\section{KẾT LUẬN VÀ ĐỀ XUÂT}

\subsection{Kết luận}

Tưới dung dịch dinh dưỡng Johnson cho cây cúc đồng tiền trồng chậu trong nhà màng qua hệ thống tưới nhỏ giọt giúp gia tăng chiều cao cây, số rễ, chiều dài phát hoa, đường kính hoa và kéo dài độ bền hoa nở (12 ngày). Cây cúc đồng tiền phát triển tốt trên giá thể phân rơm hoặc mụn xơ dừa + phân rơm (tỉ lệ 1:1) giúp gia tăng chiều cao cây, số lá, số rễ, chiều dài phát hoa và đường kính hoa.

\section{2. Đề xuất}

Áp dụng hệ thống tưới nhỏ giọt với dung dịch dinh dưỡng Johnson kết hợp sử dụng giá thể phân rơm hoặc mụn xơ dừa kết hợp với phân rơm (tỉ lệ $1: 1)$ để sản xuất cúc đồng tiền trồng chậu trong điều kiện nhà màng.

Tiếp tục nghiên cứu ảnh hưởng tương tác giữa kỹ thuật canh tác và phân bón đến chất lượng của hoa cúc đồng tiền trồng chậu.

\section{TÀI LIỆU THAM KHẢO}

Adam, P. (2002). Nutritional Control in Hydroponic. In D. Savvas, and H. Passan (Eds.). Hydroponic Production of Vegetables and Ornamentals. Embryo Publications, Athens, Greece: pp 211-261.

Brun, R., Settembrino, A. and Couve, C. (2001). Recycling of nutrient solutions for Rose (Rosa hybrida) in soilless culture. Acta Horticulturae, 554: 183-191.

Edwards, D.G., and Bell, L.C. (1989). The role of aluminum in acid soil infertility - Soil management under humid conditions in Asia and Pacific. IBSRAM proceedings, No 5, pp 201-223.

Epstein, E. (1972). Mineral nutrition of plants: Principles and perspectives. New York: John Wiley \& Sons, Inc., 412 pages.

Gislerød, H. R., Selliah, R., Ayeh, K. O., \& HvoslefEide, A. K. (2005). Macro-and micronutrient nutrition of plants in greenhouses, hydroponic systems, and in vitro culture on gelled media. In Liquid Culture Systems for in vitro Plant Propagation (pp. 475-492). Springer, Dordrecht.

Johnson, H.J. (1980). Hydroponic: A guide to soilless culture. Division of Agriculture and Natural Resources. University of California. USA.

Kessler, J.R. (1999). Greenhouse production of Gerbera Daises. Extension Horticulturist. Horticulture. Auburn University.

Kilınç, S. (2005). Katı Ortam Kültürü ile Yapılan Incir Fidanı Yetiştiriciliğinde Farklı Besin Eriyiği Formülasyonlarının Fidan Kalitesi Üzerine Etkisi (Master's thesis, Adnan Menderes Üniversitesi Fen Bilimleri Enstitüsü). In Turkish with English abstract.

Ludwig, F., Guerrero, A. C., Fernandes, D. M., \& Villas Boas, R. L. (2010). Análise de crescimento de gérbera de vaso conduzida em diferentes substratos. Horticultura Brasileira, 28(1), 70-74.

Maloupa, E., Mitsios, I., Martinez, P. F., \& Bladenopoulou, S. (1992, March). Study of substrates use in gerbera soilless culture grown in plastic greenhouses. In Symposium on Soil and Soilless Media under Protected Cultivation in Mild Winter Climates 323 (pp. 139-144).

Nguyễn Bảo Toàn (2010). Giáo trình phương pháp thủy canh. Trường Đại học Cần Thơ.

Resh, H. M. (1995). Hydroponic food production. A definitive guidebook of soilless food-growing methods $\left(3^{\text {rd }}\right.$ ed.). Woodbridge press publishing company.

Savvas, D., \& Gizas, G. (2002). Response of hydroponically grown gerbera to nutrient solution recycling and different nutrient cation ratios. Scientia Horticulturae, 96(1-4), 267-280.

Şirin, U. (2011). Effects of different nutrient solution formulations on yield and cut flower quality of gerbera (Gerbera jamesonii) grown in soilless culture system. African Journal of Agricultural Research, 6(21), 4910-4919. 
Steiner, A. A. (1961). A universal method for preparing nutrient solutions of a certain desired composition. Plant and soil, 15(2), 134-154.

Taiz, L., and Zeiger, E., 1998. Plant Physiology, 2nd Ed. Sinauer Associates, Inc., Sunderland, ISBN: 0878938311, Massachusetts, U.S.A.
Thái Hoàng Phúc (2011). Thuần dưỡng và thủy canh cúc đồng tiền (Gerbera jamesonii) (luận văn thạc sĩ). Trường Đại học Cần Thơ.

Thiên Kim (2009). Nghệ thuật trồng hoa kiểng bốn mùa. Nhà xuất bản Mỹ Thuật. 41 trang. 